\begin{tabular}{c} 
Volume and Issues Obtainable at Center for Sustainability Research and Consultancy \\
Journal of Business and Social Review in Emerging Economies \\
ISSN: 2519-089X (E): 2519-0326 \\
Volume 5: No. 1, June 2019 \\
JSRᄃ \\
Journal homepage: www.publishing.globalcsrc.org/jbsee \\
\hline
\end{tabular}

\title{
Goal-setting Theory (GST) and Gamification Relationship in Increasing Mobile Fitness Apps Engagement: A Conceptual Discussion
}

\author{
${ }^{1}$ Pg Mohd Auza'e Pg Arshad, ${ }^{2}$ Rohaizat Baharun, ${ }^{3}$ Norzaidahwati Zaidin \\ ${ }^{1}$ Azman Hashim International Business School (AHIBS), Universiti Teknologi Malaysia auzae89@yahoo.com.my \\ ${ }^{2}$ Azman Hashim International Business School (AHIBS), Universiti Teknologi Malaysia m-rohaizat@utm.my \\ ${ }^{3}$ Azman Hashim International Business School (AHIBS), Universiti Teknologi Malaysia nzw@utm.my
}

\begin{tabular}{l}
\multicolumn{1}{c}{ ARTICLE DETAILS } \\
\hline History \\
Revised format: May 2019 \\
Available Online: June 2019 \\
\\
\hline Keywords \\
Goal-Setting Theory, \\
Gamification, Engagement, \\
Mobile Fitness App, Malaysian \\
Millennial Group
\end{tabular}

JEL Classification:

C78, C79

\begin{abstract}
Purpose: The main purpose of this paper is to propose a research model conceptual through the extension study of goal-setting theory (GST) and gamification on mobile fitness app user engagement among Malaysian millennial group. This paper is discussed the justification of goal-setting theory (GST) and gamification in supporting engagement relationships.

Methodology: This paper proposed a quantitative method in determine the relationship between independent and dependent variables of engagement behavior. It also used a cross-sectional design because the data will be collected in a short period of time.

Findings: The finding of this paper is expected to support the justification of goal-setting theory (GST) and gamification in explaining the user engagement relationship. It also enriches the knowledge of goal-setting theory (GST) and gamification in body of literature.

Practical Implication: A further studies should be given to the goalsetting theory (GST) and gamification in order to enhance the user engagement on mobile fitness app especially for Malaysian Millennial Group.

Social Implication: By studying goal-setting theory (GST) and gamification in mobile fitness app engagement context, it will promote a healthy and fitness lifestyle among Malaysian millennial group that also can contribute to healthy lifestyles practice in social community.
\end{abstract}

(C) 2019 The authors, under a Creative Commons AttributionNonCommercial 4.0

Corresponding author's email address: auzae89@yahoo.com.my

Recommended citation: Pg Arshad, P. M. A., Baharun, R. and Zaidin, N. (2019). Goal-Setting Theory (GST) and Gamification Relationship in Increasing Mobile Fitness Apps Engagement: A Conceptual Discussion. Journal of Business and Social Review in Emerging Economies, 5 (1), 155-164

DOI: $10.26710 /$ jbsee.v5i1.548

\section{Introduction}

In the modern age, the advancement of mobile technology and application in mobile devices such as smartphones and PC tablets has given a great impact on society that changed the life of millions of people around the globe (Jusoh, 2017). Both academician and practitioner have found that mobile technology such as mobile application (mobile apps) offer a new method of conveying an intervention message to attract and motivate user to adopt health-conscious choices channel such as mobile fitness apps (Lim and Noh, 2017). Several mobile fitness apps that 
incorporate with several persuasive features have been introduced to the market in order to engage users to adopt mobile fitness apps which allow them to feel the physical exercise experience (Higgins, 2016).

In 2015, mobile health (m-health) apps category such as mobile fitness is one of the fastest growing categories and more than half of all mobile devices user mostly from smartphone user are downloaded mobile fitness for the purpose of improving their healthy life styles (Byun, Chiu and Bae, 2018). Krebs and Duncan (2015) concluded that $58 \%$ of smartphone users have downloaded at least one of mobile fitness onto their mobile devices. Due of the increasing demand of mobile fitness apps, several sports brand provider such as Nike and Adidas are developing their own mobile fitness for their customers (Gibbs and McLaren, 2017). The vast of mobile fitness apps on the market are more focusing on consumers and the advancement of mobile apps has encouraged practitioner to develop a mobile fitness apps which more focus on consumers' requirement which contributed the growth of mobile fitness market today (Kai-Kao and Leibovitz, 2017). Smartphone based applications such as mobile fitness has offered a method for consumers which help them to monitor and motivate to engage in a healthy lifestyle (Sarcona et al., 2017).

Like other new technologies, mobile fitness apps developer faced the fundamental challenge in how to encourage user especially for new comers try out the apps with gamification concepts and engage to the apps once the using it (Lim and Young-Noh, 2017). For instance, gamified Nike mobile fitness apps faced the severe dissatisfaction and user disengaged because Nike removed some features of game mechanics such as badges in 2016 (Welch, 2016). In addition, the misjudgement from mobile fitness apps practitioner without considered the user opinion such as gamified experience can leads to the failure of engaging user (Wolf, Weiger and Hammerschmidt, 2018). Therefore, it is important for practitioner to understand how gamification is associated with mobile fitness apps and how gamified flow can nurture user to engage.

In academic research, given the recent development of mobile fitness app, formal literature which citing the gamification on mobile fitness apps remain limited. Although the gamification helps mobile fitness app developer to generate $\$ 2.8$ billion dollar in industry but there is a little evidence in academic research and literature to support that gamification improved user engagement in mobile fitness app (Peterson, 2016). Review of past academic literature depicted that some of limitation about gamification effectiveness in improving mobile fitness apps user engagement behavior. Therefore, the information above leads to shed light on the research problems and shown the opportunity for conducting the research which discussed in the next session.

\section{Problem Statement}

The understanding of impact on the user engagement on mobile fitness app is one of the fundamental elements towards on the performance of mobile fitness app. Mobile fitness app developer face the fundamental challenge on how to make people to try out the mobile fitness app and engage once they start using it (Lim and Young-Noh, 2017). In order to increase the engagement of the mobile fitness app, the group of researchers have emphasized the importance of gamification study in mobile fitness app while performing physical and fitness activities (Thomson, Nash and Maeder, 2016; Hermsen et al., 2016). This feature has been successfully used in the popular mobile fitness app such as Wii Fit that improved user engagement in physical activity (Chao, Scherer, Wu, Lucke and Montgomery, 2013).

Since the ultimate objective of gamification is to improved user engagement behavior through the application of game design and element in non-game context, scholars have argued and criticise the notion of gamification. Burke (2014) argued that the purpose of gamification is to change the behavior such as improve engagement but it is more on to develop the skills and drive innovation among user. Robson et al. (2016) supported this notion and proposed that gamification can be only defined as user engagement through the application of game design and game mechanics principles in non-game context with user self-development skills.

Theoretically, there had been variety of engagement theory and model used by scholars to cater the engagement behavior in mobile fitness app. Engagement variables are studied in mobile fitness app to analyzed individual reactions to different initiatives. Some of scholars proposed to study game design and game mechanics known as gamification in explaining the engagement behavior (Hofacker et al., 2016). However, most of gamification study are limited and focused on education context only and there is a lack of theoretical connection which causes the shortcomings in explaining the engagement behavior (Bui et al., 2015; Berkling and Thomas, 2013). 
Only few of scholars investigated the application of gamification as an antecedent in explaining the engagement behavior on mobile fitness app context (Goodwin and Ramajaun, 2017; Chen and $\mathrm{Pu}, 2014$ ) and the extension study of goal-setting theory and gamification in mobile fitness app (Lim and Noh, 2017; Arraya et al., 2015), which cannot truly represent the user engagement explanation on mobile fitness app context. The reviews of the existing literature of goal-setting theory research revealed that most of scholars extend goal-setting theory on organisational engagement context (Bipp and Kleingeld, 2017; Smith et al., 2017).

Thus, to fill of the research gap as mentioned on above of the discussion, this research seems to proposed a comprehensive research framework by including all potential variables of goal-setting theory and gamification that may influence individual to engage in new technology and the mobile fitness app.

\section{Literature Review}

\subsection{Engagement Behavior}

Engagement relationships has been attracting among practitioners as well as academician in recent years. The technological innovation in mobile devices increasingly required practitioners to engage their customers at all possible touch points (Islam and Rahman, 2016). Engagement relationships can be defined as the approach to create, build and enhance individual relationships (Brodie et al., 2013) and as an imperative strategy to build a sustainable competitive advantage (Brodie et al., 2013; Van Doorn et al., 2010). Browden (2009) proposed that engagement views as a psychological process which involved cognitive and emotional aspects. He illustrates that engagement as an interactive process on commencing with satisfaction and as the part of culminating loyalty where the transitional pathway to loyalty captures the calculative, affective commitment, trust, involvement and customer delight. However, Van Doorn et al. (2010) argued that engagement is a primarilMy behaviors to the specific customer activity based on types or patterns. Based on these two arguments, it shows that the engagement conceptualization is still on the mixed opinions which required to extend the engagement concepts.

A number of scholars have considered the considered the consequences of engagement which included the concept of perceived value (Kim, Kim and Wachter, 2013), satisfaction (Hapsari, Clemes and Dean ,2017; Khan, Rahman and Fatma, 2016; Kim, Kim and Wachter, 2013), brand image (Hapsari, Clemes and Dean, 2017; Greve et al., 2014) and time convenience and interactivity (Kim and Baek, 2017). Among the number of the engagement consequences, not many scholars extend the study of gamification constructs as the consequences of user engagement in academic literature and research although scholars have provided the details on how gamification could conceptualize the user engagement in mobile application such as mobile fitness app (Hofacker et al., 2016). Thus, the engagement studies in information technology has faced the issues and challenge to convince the fact that user would engage and accept information technology and application. Therefore, this study extends the understanding of engagement conceptualization by focusing on mobile fitness apps engagement because this app is related on user engagement behavior.

\subsection{Gamification}

The development and innovation of multiple technology application with features games has brought the new trend known as gamification. It has become a fast- emerging business practices in worldwide industry (Yang, Asaad and Dwivedi, 2017). The term of gamification initially introduced by Nick Pelling in 2002 and it started gain the popularity in information systems (IS) academics around 2010 (Liu, Santhanam and Webster, 2017). The co-author of "Game Based Marketing" books Gabe Zichermann defined gamification as "the art of turning your customer's daily interaction into gaming experience that serve the business purposes" (Zichermann and Liner, 2010).

Based on insights from the group of scholars and extensive literature review on gamification concepts, the group of scholars extended gamification definition in different contexts. Early scholar such as Deterding et al. (2011) defined gamification concepts as the practice of applying game elements such as gamefulness, gameful interactions and gameful design with a specific intention in mind. Werbach and Hunter (2011) improved the conceptual definition of gamification concept as the application of game elements and design principle into non-game context in order to create engagement relationship among users.

Hofacker et al. (2016) suggested that gamification should be studied by looking human behavior psychology perspectives because it considered as an external motivator that appeal human to act through game design and mechanics experience. They defined it as the practice of game elements and principles in non-game design context such as human psychology behavior and reaction through enhancement of the consumer value and encouraging 
value creation of behavioral psychology outcomes such as engagement, greater loyalty or product advocacy. Therefore, it is crucial to extend the studies on gamification and how gameful elements motivate user to perform desired activities which interpret the behavioral such as engagement.

Although gamification positively enhance the engagement and acceptance behavior but some of scholars found that there is an issue that occurred on the study of gamification constructs such as lack of research context (Sanmugam et al. ,2014) and small sample size (Hamzah et al., 2015). Therefore, it is important to extend the study of gamification constructs in different context for better justification (e.g, Khaleel et al.,2016; Hong and Masood, 2014). From researcher knowledge, there is no scholars extend the study of gamification in different context such as mobile fitness app because it is also related with the engagement behavior as suggested by scholars (Seman and Ramayah, 2017). Hence, the paper aims to filling this gap by studying the gamification relationship with engagement behavior in mobile fitness app context.

\subsection{Goal-Setting Theory (GST)}

Goal-setting theory is originally introduced by Locke (1968) who proposed that the individual desired behavior is achieved when the specific goals is clear. It has been applied for decades among scholars because it helps to explain the individual motivation to perform better in related tasks and performance which related in many contexts through the setting and monitoring goals (Locke and Latham, 2002). This theory is developed based on the findings from various empirical studies which posited that user behavior is directly related to the individual's goals for pursuing with the relevant content (the object of an action) and the intensity (the amount of effort to achieve the goal) (Locke and Latham, 2002).

Goal setting theory theorized that goal core as the immediate regulators of individual behavior and the standard used to evaluate the task performance (Kylo and Landers, 1995; Locke and Latham, 1984). Goal core identify as the specific, measurable and commitment as the major inputs that provide an external referent such as time, space or increment to track the progress of goal achievement that reduce the ambiguity that allow to focus on precise action and behavior that related to goal achievement (Miner, 2003; Locke and Latham, 1990). Locke and Latham (2002) concluded that the more specific, measurable and higher commitment set by individual or organization, the more explicitly performance would be affected and lead them to achieve the target goals.

Based on research notes by Locke and Latham (2006) on goal-setting theory application, they recommended that goal-setting theory should be extend by scholars by looking an individual behavior such as engagement from different context instead of organization. Mento, Steel and Karen (1987) furthered the goal-setting theory in organizational setting and obntained the conclusion that there is a positive relationship between goal core and goal mechanism which increased their task performance that are most worthy of serious consideration. DeWalt et al. (2009) found that there is a direct correlation between those who achieved the set of goal core would motivate to create additional strategy or add more mechanism to the task performance based on feedback. Parker, Jimmieson and Amiot (2009) found that autonomy as goal mechanism improved their self-efficacy which improved their task performance towards reaching the goals. Thus, the idea and concepts of goal-setting theory helps to motivate and teams to perform better and engage more in different context (Sorrentino, 2006).

This research lends an additional support from goal-setting theory to the research model and previous body of research suggests that most of gamification design and methods are include some way of goals setting at both the organizational level as well as the individual level (e.g, Morschheuser et al., 2017; Mo-ra et al., 2017). For instance, Jacobs (2013) examined the gamification implementation by looking individual perspectives in organizations and it noted that goals as the center of the model but it does not investigate the relationship between gamification and goal-setting theory. Based on research notes by Locke and Latham (2006) on goal-setting theory application, they recommended that goal-setting theory should be extend by scholars by looking an individual behavior such as engagement from different context instead of organization such as mobile fitness app. Thus, this study will look the extension of goal-setting theory in explaining an individual goal on engagement behavior in mobile fitness app context.

\section{Underpinning Theory}

\subsection{Self-Determination Theory (SDT)}

Self-Determination theory (SDT) (Deci and Ryan, 1985;2002) is one of the general theories of motivation that systematically support the dynamics of human needs, motivation and well-being within the immediate social 
context. This theory proposed that humans' have three universal and basic needs such as autonomy (have a sense of control and agency), competency (feeling competent with tasks and activities) and relatedness (feeling included or affiliated with others) that required an individual's experience that elaborated sense of self and achieve a better psychological well-being through the satisfaction of the three basic needs (Deci and Ryan, 1985).

Instead of supporting the dynamics of human needs, Self-Determination theory (SDT) explained on how human achieve their goals or perform activities based on their psychological or cognitive responses which constitute the different form of motivation on a continuum (Deci and Ryan, 1991). This theory also posited that intrinsically motivated people who have the highest level of self-determination that undertaking behaviors for reasons of interest and inherent satisfaction. In addition, there is the existence of extrinsic motivation that also regulate the behavior such as external (controlled), introjected (to avoid guit or shame), identified (personally endorsed) and integrated regulation (congruent with values, goals and needs that are part of self) (Ryan and Deci, 2000).

Previous research identified that the constructs of Self-Determination theory (SDT) were good predictor and support the justification of human actual behavior such as engagement (Weinstein and Ryan, 2010; Hagger and Chatzisarantis, 2009; Ryan and Deci, 2006; Ryan, Rigby and Przybylski, 2006). In addition, the research that used Self-Determination theory as underpinning theory have supported the justification in explained the frequently practiced goal-directed behaviours (Hagger and Chatzisarantis, 2009; Hagger, Chatzisarantis and Harris, 2006). There is also an extensive evidence that Self-Determination theory (SDT) supported the justification of indirect effect on target behavior through the intervene variable role (Hagger and Chatzisarantis, 2009; Standage, Duda and Ntoumanis, 2003; Hagger et al., 2002) as well as supported the justification of direct effect on behavior (Lavergne et al., 2010; Sheldon et al., 2003; Green-Demers, Pelletier and Menard, 1997; Grolnick and Ryan, 1987). In this study, Self-Determination theory (SDT) in supporting the justification of goal-setting theory and gamification in mobile fitness app engagement.

\section{Research Model Framework}

The research model framework for this study is designed as below:

Figure 1: A Proposed of Research Model Framework

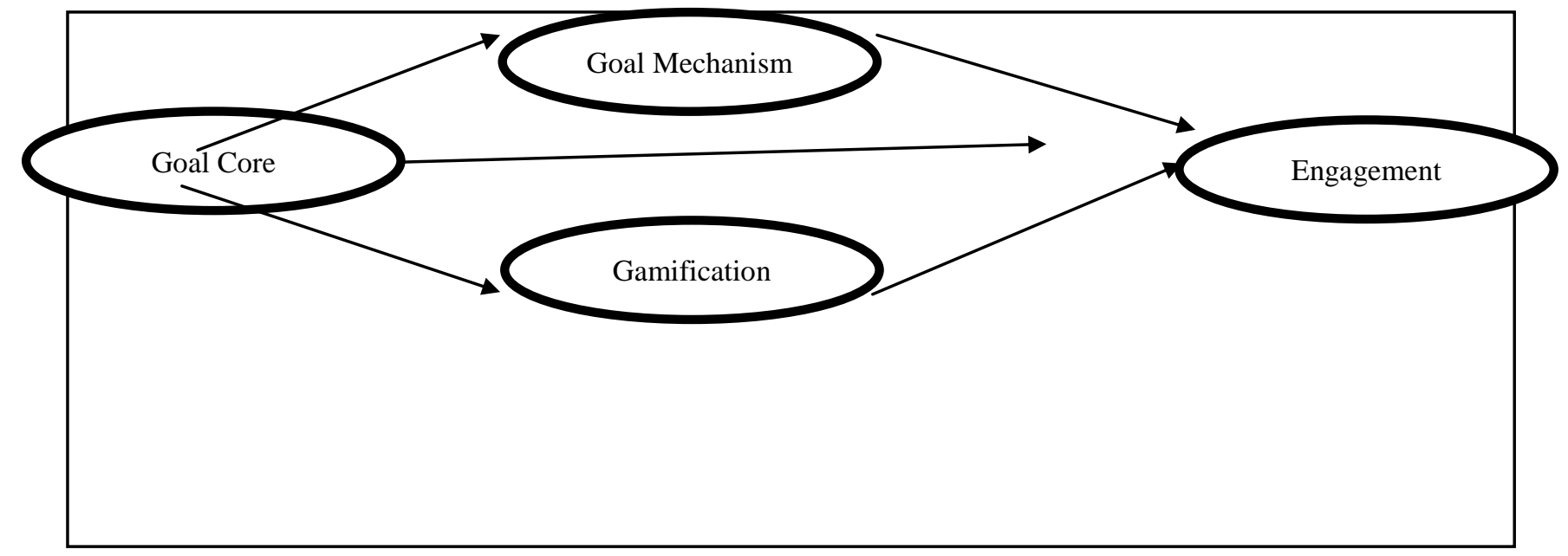

\section{List of Propositions}

Although there are a lot of antecedents and factors that have been identified as important determinant of an individual engagement, this paper aims to achieve the objective as to provide the explanation of gamification and goal-setting theory in mobile fitness app user engagement. Thus, the hypotheses are proposed as follows:

H1: Goal core positively related with Engagement

H2: Goal core positively related with Goal Mechanism

H3: Goal core positively related with Gamification

H4: Goal Mechanism positively related with Engagement

H5: Gamification positively related with Engagement 


\section{Methodology}

This study proposed a quantitative approach. It is a hypothetical deductive research design because it is aimed to generate the knowledge and identifying the relationship between the independent and dependent variables of engagement. Cross-sectional design is applied because the data collection will be conducted in a short period of time. Convenience and purposive sampling are being used to select Malaysian millennial group who used mobile fitness app and joining the fitness training in Klang Valley area. The reason of selected Malaysian millennial as the target of respondents because they are major mobile fitness app user (Archana and Heejin, 2008) and highest number of mobile fitness app downloader (Robinson, 2006). A total of 400 questionnaires will be distributed among them.

\section{Implication and Recommendation For Future Research}

The extension study of goal-setting theory (GST) and gamification in mobile fitness app can encourage a fitness and healthy lifestyles which can reflect the daily lifestyles of millennial group. The knowledge of this paper is expected to provide the recommendation on engagement knowledge for fitness instructors and fitness centre who are wished to extend their fitness market strategy in mobile application. Furthermore, the results on this research is expected to be useful for game designer in develop the application of gamification in persuade the potential user to engage. It also contributes a wider understanding of mobile fitness app developer especially on how to encourage mobile fitness app users to engage and avoid the abandonment in future. Moreover, it provides effective guidance for mobile health and service marketing industry in developing engagement strategic plans to promote fitness lifestyles by including gamification role in mobile fitness app in future.

This study should extend the discussion on how the application of goal-setting theory and gamification towards the engagement behavior in mobile fitness app. Future research is recommend to investigate on the relationship of engagement behavior from goal-setting theory and gamification in various research context to gain in-depth knowledge about the engagement behavior.

\section{Conclusion}

There are rising number of researches of engagement in mobile healthcare application such as mobile fitness apps. In same vein, the application of goal-setting theory (GST) and gamification have been extended by the group of scholars by looking in engagement behavior in various of research context. However, most of the application of goal-setting theory are being conducted in organizational settings while gamification in education engagement. Surprisingly, there is a dearth of goal-setting theory and gamification study in engagement behavior in academic research. Hence, it is advisable for future research to extend this study of goal-setting theory and gamification in order to look the engagement in mobile application such as mobile fitness app.

This research is worthwhile to be extend because the results of this research can contribute the body of knowledge in engagement research especially in individual engagement justification in mobile application such as mobile fitness app. It also helps mobile fitness app practitioner and developer in increasing the user engagement on their apps through the understanding of goal-setting theory (GST) and gamification research. More research on the extension of goal-setting theory (GST) and gamification especially on the engagement of mobile fitness app are encouraged since there is a limitation of this research.

\section{REFERENCES}

Arraya, M. A., Pellissier, R., and Preto, I. (2015). Team goal-setting involves more than only goal-setting. Sport, Business and Management: An International Journal. 5(2) :157-174.

Archana K., Heejin L. (2008), Age differences in mobile service perceptions: comparison of Generation Y and baby boomers, Journal of Services Marketing, 22(7)

Berkling, K., and Thomas, C. (2013). Gamification of a Software Engineering course and a detailed analysis of the factors that lead to its failure. In Interactive Collaborative Learning (ICL), 2013 International Conference on. 525-530. IEEE.

Brodie, R. J., Ilic, A., Juric, B., and Hollebeek, L. (2013). Consumer engagement in a virtual brand community: An exploratory analysis. Journal of Business Research. 66(1): 105-114.

Bui, A., and Veit, D. (2015). The Effects of Gamification on Driver Behavior: An Example from a Free Float Carsharing Service. In ECIS.

Burke, B. (2014). Gartner redefines gamification. Gartner Blog Network. 
Byun, H., Chiu, W., and Bae, J. S. (2018). Exploring the Adoption of Sports Brand Apps: An Application of the Modified Technology Acceptance Model. International Journal of Asian Business and Information Management (IJABIM). 9(1): 52-65.

Chao, Y.-Y., Scherer, Y. K., Wu, Y.-W., Lucke, K. T., and Montgomery, C. A. (2013). The feasibility of an intervention combining self-efficacy theory and Wii fitexer-games in assisted living residents: A pilot study. Geriatric Nursing. 34(5) : (377-382)

Deci, E., and Ryan, R. M. (1985). Intrinsic motivation and self-determination in human behavior. Springer Science \& Business Media.

Deterding S, Dixon D, Khaled R and Nacke L (2011). From game design elements to gamefulness: Defining gamification. In: Academic MindTrek Conference: Envisioning Future Media Environments. 2011 Presented at: Proc 15th International Academic MindTrek Conference: Envisioning Future Media Environments. ACM.

Gibbs, S. (2016, February 12). Runkeeper bought by Asics in latest sports brand app acquisition. The Guardian. Retrieved March 22, 2017, from: https://www.theguardian.com/technology/2016/feb/12/runkeeper-asicssports-brand-appacquisition

Green-Demers, I., Pelletier, L. G., \& Menard, S. (1997). The impact of behavioural difficulty on the saliency of the association between self-determined motivation and environmental behaviours. Canadian Journal of Behavioural Science ,29(3), 157.

Greve, G. (2014). The moderating effect of customer engagement on the brand image-brand loyalty relationship. Procedia-Social and Behavioral Sciences. 148: 203-210.

Grolnick, W. S., \& Ryan, R. M. (1987). Autonomy in children's learning: An experimental and individual difference investigation. Journal of Personality and Social Psychology, 52(5), 890.

Hagger, M. S., and Chatzisarantis, N. L. (2009). Integrating the theory of planned behaviour and self-determination theory in health behaviour: A meta-analysis. British Journal of Health Psychology, 14(2), 275-302.

Hagger, M. S., Chatzisarantis, N. L., and Biddle, S. J. (2002). A meta-analytic review of the theories of reasoned action and planned behavior in physical activity: Predictive validity and the contribution of additional variables. Journal of Sport and Exercise Psychology, 24(1), 3-32.

Hair, J. F., Black, W. C., Basin, B. J., and Anderson, R. E. (2010). Multivariate data

Hamzah, W. M. A. F. W., Ali, N. H., Saman, M. Y. M., Yusoff, M. H., and Yacob, A. (2015). Influence of gamification on students' motivation in using e-learning applications based on the motivational design model. International Journal of Emerging Technologies in Learning, 10(2), 30-34.

Hapsari, R., Clemes, M. D., and Dean, D. (2017). The impact of service quality, customer engagement and selected marketing constructs on airline passenger loyalty. International Journal of Quality and Service Sciences. 9(1): 21-40.

Hapsari, R., Clemes, M. D., and Dean, D. (2017). The impact of service quality, customer engagement and selected marketing constructs on airline passenger loyalty. International Journal of Quality and Service Sciences. 9(1): 21-40.

Hermsen, S., Frost, J., Renes, R. J., and Kerkhof, P. (2016). Using feedback through digital technology to disrupt and change habitual behavior: A critical review of current literature. Computers in Human Behavior.5 :, 61 (74).

Higgins, J. P. (2016). Smartphone applications for patients' health and fitness. The American Journal of Medicine. 129(1): 11-19.

Hofacker, C. F., De Ruyter, K., Lurie, N. H., Manchanda, P., and Donaldson, J. (2016). Gamification and mobile marketing effectiveness. Journal of Interactive Marketing, 34, 25-36.

Hong, G. Y., and Masood, M. (2014). Effects of gamification on lower secondary school students' motivation and engagement. International Journal of Social, Education, Economics and Management Engineering, 8(12), 3483-3490.

Islam, J. U., and Rahman, Z. (2016). Linking customer engagement to trust and word-of-mouth on Facebook brand communities: An empirical study. Journal of Internet Commerce. 15(1) :40-58.

Jusoh, S. (2017). A Survey on Trend, Opportunities and Challenges of mHealth Apps. International Journal of Interactive Mobile Technologies . 11(6): 73-85.

Khaleel, F. L., Ashaari, N. S., Meriam, T. S., Wook, T., and Ismail, A. (2015). The study of gamification application architecture for programming language course. In Proceedings of the 9th International Conference on Ubiquitous Information Management and Communication (p. 17). ACM.

Khan, I., Rahman, Z., and Fatma, M. (2016). The role of customer brand engagement and brand experience in online banking. International Journal of Bank Marketing. 34(7): 1025-1041. 
Kim, H., Lee, H. J., Cho, H., Kim, E., and Hwang, J. (2018). Replacing Self-Efficacy in Physical Activity: Unconscious Intervention of the AR Game, Pokémon GO. Sustainability. 10(6): 1-13.

Kim, Y. H., Kim, D. J., and Wachter, K. (2013). A study of mobile user engagement (MoEN): Engagement motivations, perceived value, satisfaction, and continued engagement intention. Decision Support Systems. 56: 361-370.

Krebs, P., and Duncan, D. T. (2015). Health App Use among US Mobile Phone Owners: a national survey. JMIR mHealth and uHealth. 3(4).

Kylo, L. B., and Landers, D. M. (1995). Goal setting in sport and exercise: A research synthesis to resolve the controversy. Journal of Sport and Exercise Psychology. 17(2): 117-137.

Lavergne, K. J., Sharp, E. C., Pelletier, L. G., \& Holtby, A. (2010). The role of perceived government style in the facilitation of self-determined and non self-determined motivation for pro-environmental behavior. Journal of Environmental Psychology, 30(2), 169-177.

Lim, J. S., and Noh, G. Y. (2017). Effects of gain-versus loss-framed performance feedback on the use of fitness apps: Mediating role of exercise self-efficacy and outcome expectations of exercise. Computers in Human Behavior. 77: 249-257.

Lim, J. S., and Noh, G. Y. (2017). Effects of gain-versus loss-framed performance feedback on the use of fitness apps: Mediating role of exercise self-efficacy and outcome expectations of exercise. Computers in Human Behavior. 77: 249-257.

Liu, D., Santhanam, R., and Webster, J. (2017). Toward Meaningful Engagement: A Framework For Design And Research Of Gamified Information Systems. MIS quarterly. 41(4).

Locke, E. A., and Latham, G. P. (2002). Building a practically useful theory of goal setting and task motivation: A 35-year odyssey. American Psychologist. 57(9): 705.

Locke, E. A., and Latham, G. P. (2006). New directions in goal-setting theory. Current Directions in Psychological Science. 15(5): 265-268.

Locke, E. A., Cartledge, N., and Koeppel, J. (1968). Motivational effects of knowledge of results: A goal-setting phenomenon?. Psychological Bulletin. 70(6p1): 474.

Miner, J. B. (2003). The rated importance, scientific validity, and practical usefulness of organizational behavior theories: A quantitative review. Academy of Management Learning and Education. 2(3): 250-268.

Mora, D. Riera, C. Gonzalez, and J. Arnedo-Moreno (2017). Gamification: a systematic review of design frameworks. Journal of Computing in Higher Education. 1-33.

Morschheuser, B., Hamari, J., Koivisto, J., and Maedche, A. (2017). Gamified crowdsourcing: Conceptualization, literature review, and future agenda. International Journal of Human-Computer Studies. 106: 26-43.

Peterson S. (2014). Gamification market to reach \$2.8 billion in 2016. Retrieved January 23, 2017, from: http://www.gamesindustry.biz/articles/2012-05-21-gamification-market-to-reach-USD2-8-billion-in-2016.

Robson, K., Plangger, K., Kietzmann, J. H., McCarthy, I., and Pitt, L. (2016). Game on: Engaging customers and employees through gamification. Business Horizons. 59(1): 29-36.

Robinson, L. (2006). Customer Expectations of Sport Organizations, European Sport Management Quarterly.6: 684.

Ryan, R. M., and Deci, E. L. (1991). Inner resources for school achievement: Motivational mediators of children's perceptions of their parents. Journal of educational psychology, 83(4), 508.

Ryan, R. M., Rigby, C. S., \& Przybylski, A. (2006). The motivational pull of video games: A self-determination theory approach. Motivation and Emotion, 30(4), 344-360.

Sanmugam, M., Mohamed, H., Zaid, N. M., Abdullah, Z., Aris, B., and Suhadi, S. M. (2016). Gamification's role as a learning and assessment tool in education. International Journal of Knowledge-Based Organizations, 6(4), 28-38.

Sarcona, A., Kovacs, L., Wright, J., and Williams, C. (2017). Differences in eating behavior, physical activity, and health-related lifestyle choices between users and nonusers of mobile health apps. American Journal of Health Education. 48(5): 298-305.

Sekaran, U. (2003). Research methods for business: a skill-building approach. (4th ed.).

Seman, S. A. A., and Ramayah, T. (2017). Are We Ready to App?: A Study on mHealth Apps, Its Future, and Trends in Malaysia Context. In Mobile Platforms, Design, and Apps for Social Commerce (69-83). IGI Global.

Smith, D. C., Smith, M. R., Sweeney, C., Elfiky, A. A., Logothetis, C., Corn, P. G., and Vaishampayan, U. N. (2017). Cabozantinib in patients with advanced prostate cancer: results of a phase II randomized discontinuation trial. Journal of Clinical Oncology. 31(4): 412.

Standage, M., Duda, J. L., and Ntoumanis, N. (2003). A model of contextual motivation in physical education: 
Using constructs from self-determination and achievement goal theories to predict physical activity intentions. Journal of Educational Psychology, 95(1), 97.

Thomson, C., Nash, J., and Maeder, A. (2016). Persuasive design for behaviour change apps: Issues for designers. In Proceedings of the Annual Conference of the South African Institute of Computer Scientists and Information Technologists (p. 43). ACM.

Van Doorn, J., Lemon, K. N., Mittal, V., Nass, S., Pick, D., Pirner, P., and Verhoef, P. C. (2010). Customer engagement behavior: Theoretical foundations and research directions. Journal of Service Research. 13(3): 253-266.

Weinstein, N., and Ryan, R. M. (2010). When helping helps: Autonomous motivation for prosocial behavior and its influence on well-being for the helper and recipient. Journal of Personality and Social Psychology, 98(2), 222.

Welch, C. 2016. "Google: Android App Downloads Have Crossed 50 Billion, over 1m Apps in Play. The Verge [July 24, 2013]." Retrieved March 23, 2017, from: https://www.theverge.com/2013/7/24/4553010/google50-billion-android-app-downloads-1m-apps-available

Werbach, K., and Hunter, D. (2012). The gamification toolkit. Dynamics, mechanics and components for the win. Pennsylvania: Wharton Digital Press.

Wolf, T., Weiger, W. H., and Hammerschmidt, M. (2018). Gamified Digital Services: How Gameful Experiences Drive Continued Service Usage.

Yang, Y., Asaad, Y., and Dwivedi, Y. (2017). Examining the impact of gamification on intention of engagement and brand attitude in the marketing context. Computers in Human Behavior. 73: 459-469.

Zichermann, G., and Linder, J. (2010). Game based marketing: Inspire customer loyalty trough rewards. GameBased Marketing. 240. 